\title{
Mid-Trimester Scan is better for Detecting Congenital Anomalies: An Experience from Dhulikhel Hospital
}

\author{
Tamrakar SR ${ }^{1}$, Shrestha $\mathrm{R}^{2}$
}

\section{ABSTRACT}

Introduction: Ultrasound is a valuable diagnostic tool for detecting the congenital anomalies in the fetus. Congenital anomalies are detected in $14 \%$ of new born. Major anomalies are detected in 2 to $5 \%$ of new born. This accounts for $20 \%$ to $30 \%$ of total perinatal deaths. Prenatal diagnosis provides variety of management options for the pregnant women ranging from termination of pregnancy, elective delivery or intrauterine manipulation of the anomalies. Aims: To determine the prevalence of the fetal congenital anomalies at 20- 24 weeks ultrasonography. Methods: This is prospective study conducted at Dhulikhel Hospital. Pregnant ladies with singleton pregnancy at 20 to 24 weeks were enrolled for transabdominal ultrasound for detecting congenital anomalies. Results: Of 1027 pregnant ladies screened, anomalies were detected in 31 ladies during mid trimester ultrasound. The overall prevalence of congenital anomalies detected in our study is $3.02 \%$ (31 cases), which has sensitivity of $87.8 \%$, specificity of $99.7 \%$ and positive predictive values of $93.5 \%$. In our study, mean gestational age during scan was $21^{+5}$ weeks of gestation. And 13 pregnant ladies pregnancies were terminated between 20-24 weeks for having major congenital anomaly in fetus. Conclusion: Mid trimester ultrasonography is a valuable method for pregnant ladies to detect the congenital anomalies in fetus. When major anomalies are detected, timely termination of pregnancy have saved the cost and tragedy of losing viable fetus.

\section{Keywords: Congenital anomalies, Mid trimester, Transabdominal ultrasound}

\section{Authors:}

1. Prof. Dr. Suman Raj Tamrakar

2. Dr. Rubina Shrestha

${ }^{1}$ Department of Obstetrics and Gynecology, Dhulikhel Hospital, Kathamandu University of School Medical Sciences, Dhulikhel

${ }^{2}$ Department of Obstetrics and Gynecology, College of Medical Sciences, Bharatpur

\section{Address for Correspondence:}

Prof. Dr. Suman Raj Tamrakar

Department of Obstetrics and Gynaecology

Dhulikhel Hospital, Kathamandu University of School Medical Sciences, Dhulikhel

E-mail: drsuman3947@gmail.com

\section{INTRODUCTION}

The clinical application of ultrasound in medical diagnosis was first introduced and popularized by Sir lan Donald in 1958 by diagnosing a large ovarian cyst. A few years later, he published his study of fetal head measurement. ${ }^{1}$ Further evolution has led the use of ultrasound for different purposes diagnostic as well as therapeutic in surgery, obstetrics and gynecology, medicine etc. In 1972 Campbell first reported the prenatal diagnosis of anencephaly. ${ }^{2}$ Every pregnant woman desires to have healthy baby. The detection, treatment and prevention of congenital anomalies are considered important goals of antenatal care. One of the routine antenatal investigations, ultrasound has been a valuable diagnostic tool and screening tool for practicing obstetrician. Obstetric ultrasound employ frequencies of 2 to $15 \mathrm{MHZ}$ Abdominal transducers use a frequency of 2 to 6.5 $\mathrm{MHZ}$ and transvaginal transducer use frequencies of 5 to 15 MHZ. Obstetric ultrasound uses largely abdominal approach. Information may be displayed as a sagittal, coronal, axial or oblique section. Ultrasound has been a valuable diagnostic tool for determining early pregnancy, gestation age, evaluation of fetal growth and well-being. There are specific indications for ultrasonography (USG) in first, second and third trimester (Table I). ${ }^{3}$ Special benefits of routine ultrasound examination at mid-trimester has been the detection of congenital anomalies which was confirmed by the Helsinki trial. ${ }^{4}$ Eik-Nes et al. concluded that screening for congenital anomalies decreased unnecessary inductions and reduced perinatal morbidity and mortality. ${ }^{5}$ 


\begin{tabular}{|c|c|}
\hline First trimester & Second Trimester/ Third trimester \\
\hline $\begin{array}{l}\text { - } \quad \text { Confirm an intrauterine } \\
\text { pregnancy } \\
\text { Estimate the gestational age } \\
\text { - } \quad \text { Donfirm the cardiac activity } \\
\text { Diagnose the multi fetal } \\
\text { gestation including amnionicity } \\
\text { and chorionicity. } \\
\text { - Assessment of embryonic/fetal } \\
\text { anatomy appropriate for the first } \\
\text { trimester such as anencephaly. } \\
\text { Evaluate the maternal pelvic } \\
\text { masses or uterine abnormalities. } \\
\text { Measure nuchal translucency } \\
\text { as a part of screening for fetal } \\
\text { aneuploidy. }\end{array}$ & $\begin{array}{ll}\text { - } & \text { Gestational age estimation } \\
\text { - } & \text { Setal-growth evaluation } \\
\text { - } & \text { date discrepancy } \\
\text { - } & \text { Diagnose multifetal gestation } \\
& \text { Fetal anatomical evaluation } \\
\text { - } & \text { Measurement anomaly screening. } \\
& \text { length } \\
\text { - } \quad \text { Placental localization } \\
\text { - } \quad \text { Confirmation of fetal } \\
\text { - } \quad \text { presentation } \\
\text { - } \quad \text { oligohydramnion of hydramnios or } \\
\text { - } \quad \text { Suspected fetal death }\end{array}$ \\
\hline
\end{tabular}

Table I : Trimester-wise obstetric ultrasound indication

Congenital anomalies can be defined as structural or functional anomalies (e.g. metabolic disorders) that occur during intrauterine life and can be identified prenatally, at birth or later in life. ${ }^{6}$ The congenital anomalies encompass genetic disorders, chromosomal anomalies and dimorphic developmental anomalies in isolation or in combination. There are various screening techniques, noninvasive technique and invasive technique for prenatal diagnosis of congenital anomalies. Detection of structural anomalies by the obstetric ultrasound is one of the non-invasive techniques. Technical advances in ultrasound have helped in easy detection of structural anomalies since few decades. ${ }^{7}$

Congenital malformations are divided into major and minor categories. The RADIUS (Routine Antenatal Diagnostic Imaging with Ultrasound) study defined major anomaly as birth defects that required medical or surgical intervention and/ or had a significant impact from a functional or cosmetic perspective. ${ }^{8}$ And minor anomalies are the features that vary from those seen in the normal population but that, in and of themselves, do not cause increased morbidity. Prenatal detection of congenital anomalies may characteristically alter obstetric management. Antenatal diagnosis of significant fetal anomalies offers a variety of options for the pregnant women ranging from termination of pregnancy to elective delivery at a center, equipped to perform highly specialized neonatal surgical procedure. ${ }^{9}$

\section{METHODS}

This prospective study was conducted in the Department of Obstetrics and Gynaecology of Dhulikhel Hospital from January 2015 to August 2016. This is a tertiary level hospital where more than 3500 deliveries take place annually. In this study, primigravida ladies at 20- 24 weeks are enrolled for transabdominal ultrasound for detecting congenital anomalies. Exclusion criteria include multigravida, multifetal gestation, maternal diabetes and maternal obesity.
Altogether 3998 pregnant ladies came for antenatal visit during the study period. Among them 1648 (41.2\%) were primigravida. Out of 1648 primigravida pregnant ladies, 1242 met all the inclusion criteria. All these ladies were counselled and informed consents were taken. Out of 1242 enrolled pregnant ladies, 215 patients lost the follow-up. Hence, rest 1027 primigravida ladies were included in this study.

Ultrasound scan are carried out by professional Radiologist. TAS was performed between $20-24$ weeks of gestation. It is the ideal time for the sonographic assessment of fetal anatomy as there is an optimal balance between the amount of amniotic fluid volume and developmental stage of the fetal organs. It represents the limit of fetal viability.

Ethical clearance was taken from the hospital research committee (IRC-KUSMS\#41/15). All data were entered in excel sheet and analyzed by SPSS 16 packages using appropriate statistical tools like frequency, percentage, means, p value, Chi square test.

\section{RESULTS}

In this prospective clinical study, 1027 pregnant ladies were enrolled to find out the prevalence of congenital anomalies by mid trimester scan.

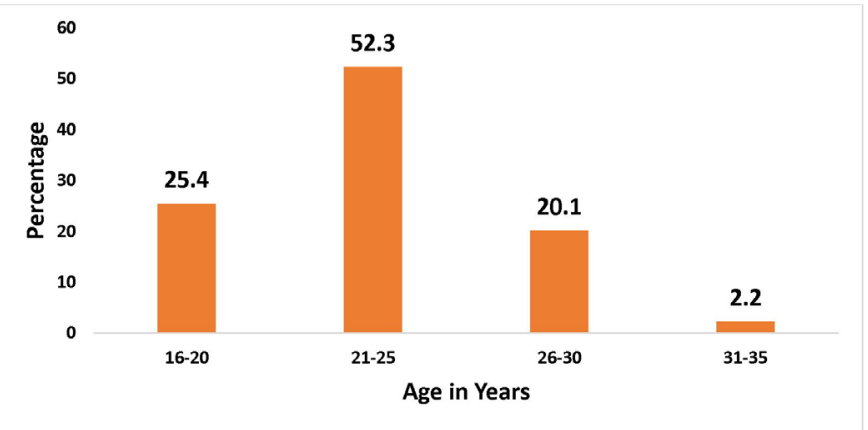

Figure 1 : Age distribution of study population

In this study, the youngest lady was 16 years old and the oldest was 35 years old. The mean age was $22.92 \pm 3.45$. More than half of the pregnant ladies were of age group between 21-25 years.

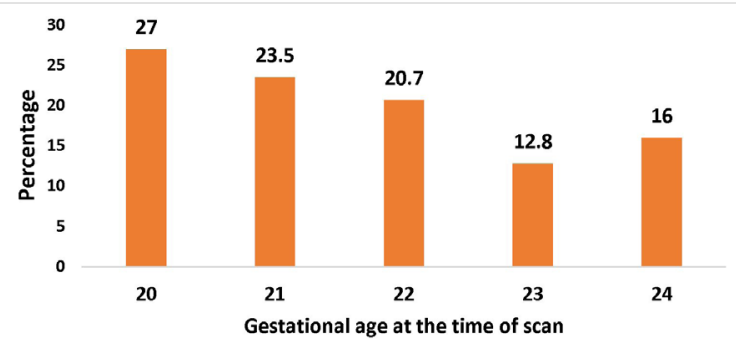

Figure 2 : Gestational age at the time of scan

In this study mean gestational age during scan was $21^{+5}$ weeks of gestation. 


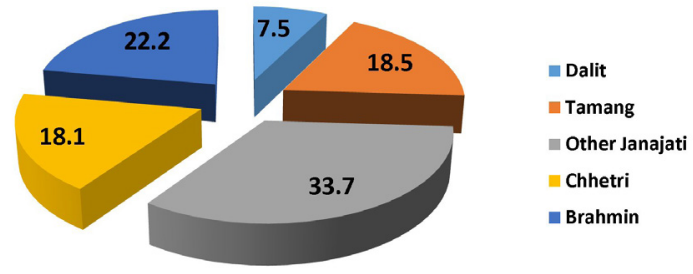

Figure 3 : Ethnicity of study population (percentage)

In this study most of the ladies belong to Janajati ethnicity and among Janajati, Newar ( $n=263,25.6 \%)$ were maximum.

\begin{tabular}{|lccc|}
\hline \multicolumn{1}{|c}{ Congenital anomaly } & Frequency & Percentage & Termination \\
\hline Anencephaly & 5 & 16.1 & Yes \\
\hline Non-immune hydrops fetalis & 3 & 9.7 & Yes \\
\hline Cleft lip and cleft palate & 4 & 12.9 & No \\
\hline $\begin{array}{l}\text { Fetal ventriculomegaly non } \\
\text { communicating }\end{array}$ & 1 & 3.2 & Yes \\
\hline Prominent ventricle & 2 & 6.4 & No \\
\hline Choroid plexus cyst & 4 & 12.9 & No \\
\hline Reduced size of cisterna magna & 1 & 3.2 & No \\
\hline Aqueductal stenosis & 1 & 3.2 & Yes \\
\hline Echogenic focus in left ventricle & 2 & 6.4 & No \\
\hline Prominent cisterna magna & 1 & 3.2 & No \\
\hline Multicystic dysplastic kidney & 1 & 3.2 & Yes \\
\hline Dilated fetal renal pelvis & 1 & 3.2 & No \\
\hline Posterior urethral valve & 1 & 3.2 & No \\
\hline Pelvic ureteric obstruction & 1 & 3.2 & No \\
\hline Dilated bowel loops with & 1 & 3.2 & No \\
\hline echogenic bowel & 1 & 3.2 & Yes \\
\hline Choledochal cyst & 1 & 3.2 & Yes \\
\hline Dandy walker malformation & 31 & & \\
\hline
\end{tabular}

Table II : Congenital anomalies detected during mid-trimester screening ( $n=31)$

Out of total 1027 pregnant ladies scanned during mid-trimester screening, congenital anomalies were detected in 3.02\% (31). Total of 13 (1.2\%) were detected to have major anomalies and rest $18(1.8 \%)$ were detected with minor anomalies. Major anomalies detected were anencephaly (5), non-immune hydrops (3), and each case of aqueductal stenosis, choledochal cyst, Dandy Walker malformation, multicystic dysplastic kidney and non-communicating ventriculomegaly. All the pregnant ladies with major congenital anomalies underwent termination of pregnancy after proper counseling. Rest were detected with minor anomalies like cleft lip and cleft palate (4), prominent ventricle (2), choroid plexus cyst (4), echogenic focus in left ventricle (2) and each case of reduced cisterna magna, dilated fetal renal pelvis, posterior urethral valve, pelvic ureteric obstruction and dilated bowel loops with echogenic bowel.

Out of 1027 cases, majority of pregnant ladies, 634 delivered at term, 160 had preterm delivery and 233 had post-dated delivery. Of them 20 pregnant ladies delivered before 28 weeks, 13 pregnant ladies pregnancies were terminated between 2024 weeks for having major congenital anomaly in fetus.

\section{DISCUSSION}

Congenital anomalies were detected in $14 \%$ of new born. ${ }^{10}$ Major anomalies are detected in $2-5 \%$ of new born. This accounts for $20 \%$ to $30 \%$ of total perinatal deaths..$^{11,12}$ In 1994 , a secondary analysis of the RADIUS study ${ }^{13}$ reported that only $17 \%$ of anomalous fetuses were detected by ultrasonography performed between 15 and 22 weeks in a low-risk population. Anomaly detection rates in other published series ranges from $21 \%$ to $84 \%{ }^{4,14-19}$ Van Dorsten JP et al. conducted ultrasonography scanning at 15-22 weeks of 2031 pregnant ladies, found that 47 fetuses $(2.3 \%$ ) had a major anomaly, $8.6 \%$ in the indicated group and $0.68 \%$ in the screening group $(p=0.001)$. The sensitivity for detecting the anomalous fetus was $75 \%$ overall, $89.7 \%$ in the indicated group and $47.6 \%$ in the screening group $(p=0.001){ }^{20}$

In Nepal, the death rate due to congenital anomalies per year is 6.56 per $100000 .{ }^{21}$ The incidence of congenital anomalies among newborn during one year at Maternity Hospital was $0.36 \%$ among the total live births which account for $9.7 \%$ of perinatal deaths, $11.06 \%$ of early neonatal death and $7.9 \%$ of still births. ${ }^{22} \mathrm{~A}$ review study conducted at TU Teaching Hospital showed about $1.3 \%$ of babies having congenital malformation was responsible for about $15 \%$ of the perinatal mortality. ${ }^{23}$ In our institute, congenital anomalies were detected in 3.02\% (31) (Table II). Certain studies have repeatedly shown that more anomalies are diagnosed if the scan is done after 18 weeks. Though a screening of congenital anomalies is carried out in the $2^{\text {nd }}$ trimester, usually between the 18th and 21st weeks of gestation, the ideal time for the sonographic assessment of fetal anatomy should be at 24- 26 weeks gestation, to give an optimal balance between the amount of amniotic fluid and the volume and developmental stage of the fetal organs. ${ }^{24}$ The Royal College of Obstetrics and Gynaecologists (RCOG) recommends that the second trimester fetal anatomical scan be performed between 20-24 weeks as most of the fetal anatomic parts are developed by this gestational age. This also helps in timely decision whether to continue or terminate the pregnancy when fetal anomaly is detected. The knowledge of fetal anatomy and its change over the antenatal period must be remembered in diagnosing malformation. For examples, the bowel returns to the fetal abdominal cavity at 10- 12 weeks. Therefore diagnosis of an omphalocele before tenth week is 
not logical. Major abnormalities of the fetal head, abdominal wall and urinary tract, and of the umbilical cord and placenta, can be reliably detected at 10-11 weeks of gestation. Detection of other anomalies such as spina bifida, diaphragmatic hernia or heart defects is limited before 13 weeks of gestation. Similarly in infantile polycystic kidney disease, the kidney and urinary bladder may appear completely normal up to 24 weeks of gestation. A diagnosis of agyria is unjustified before 20-24 week as there is relative absence of cerebral sulci before midtrimester. ${ }^{24}$

Weiszl $\mathrm{B}$ et al. found that the detection rate of fetal anomalies at $11-14$ weeks is $44 \%$ in comparison to $74 \%$ by the midpregnancy scan. ${ }^{25}$ The study by Hegge FN et al. revealed that an indication based system for ultrasound referral failed to detect any abnormal fetuses prior to 23 weeks of gestation. ${ }^{26}$ Chitty et al. retrospectively reviewed 8432 unselected pregnancies in the second trimester. There were 130 fetuses found to have an abnormality at birth or after termination of pregnancy. Ultrasound was done in 125 pregnant ladies in the second trimester. Of these, 93 cases were diagnosed (sensitivity $74.4 \%$; specificity $99.9 \%)$. In 52 cases, the pregnancy was terminated after a severe anomaly was identified. ${ }^{16}$ In our study, mean gestational age during scan was $21^{+5}$ weeks of gestation. And 13 pregnant ladies were terminated between 20-24 weeks for having major congenital anomaly in fetus. Prenatal detection of congenital anomalies may characteristically alter obstetric management. Antenatal diagnosis of significant fetal anomalies offers a variety of options for the pregnant women ranging from termination of pregnancy or elective delivery at a center equipped to perform highly specialized neonatal surgical procedure. Termination of pregnancy is done keeping in mind the abortion law. At the ground of Nepal abortion law if the fetus has severely debilitating or fatal deformity, pregnancy can be terminated at any gestation. It will help the couple to protect against psychological and mental tragedy and cost associated with caring of child with congenital anomalies. Four fetus had anomalies that probably went undetected by USG at 20-24 weeks. Two fetus had isolated ventricular septal defect and one with multiple cardiac defect and one fetus with osteogenesis imperfecta which was diagnosed later at 32 weeks. False-positive diagnosis was less in this study. In this study a combination of ultrasonographically detected anomalies and delivery detected anomalies yields an overall congenital anomaly prevalence of $3.4 \%$ in low risk pregnant ladies. There were two anomalies that resolved by the time of delivery, one case of reduced size of cisterna magna and one case of dilated fetal renal pelvis. Both of these neonates were found to be normal at birth.

In a study done by Van Dorsten JP et al. ${ }^{20}$ in 2031 pregnant ladies the overall prevalence of congenital anomaly in screening group was $1.3 \%(n=21)$ in screening group and
$2.95 \%(n=39)$ in the indicated group. For the pregnant ladies at risk of anomalies (indicated group), the accuracy of anomaly detection is extremely high compared to low risk population. The prevalence of ultrasonographically detected anomalies in our study is quiet higher even in low risk pregnant ladies, as our hospital is the tertiary center were large number of cases are referred for evaluation. The Helsinki trial showed a difference in a detection rates for anomalies (36\% vs $77 \%$ ) when non- tertiary center with tertiary centers. ${ }^{4}$ According to our study ultrasonographic screening for detecting congenital anomalies in fetus has sensitivity of $87.8 \%$ and specificity of $99.7 \%$ with high positive predictive value (PPV) of $93.5 \%$ which is quiet similar to the study done by Magriples $\mathrm{U}$ and Copel $\mathrm{JA}^{27}$ with sensitivity, specificity and PPV of $71.4 \%$, $99.4 \%$ and $80 \%$ respectively. It is quiet comparable to other studies by Van Dorsten JP ${ }^{20}$ and Chitty LS. ${ }^{16}$ Routine anomaly screening improves perinatal outcome, most directly through termination of pregnancy for major anomalies and selective delivery at tertiary centers. In this study, all the pregnant ladies who were detected to have major congenital anomalies went for termination of pregnancy after proper counselling. Termination in case of congenital anomalies is understandable in our setting because of inability of parents to bear the cost and burden associated with raising the anomalous baby.

\section{LIMITATION}

We have faced difficulty in providing appointment for detail evaluation of anomalies and it's documentation in general Radiology Department. Clients would have been benefitted and comforted more in dedicated USG room for anomalies screening purpose. And we couldn't perform the autopsy of all the expelled fetuses with major anomalies due to absence of national guideline and unwillingness of the parents.

\section{CONCLUSION}

Hence we conclude that the prevalence of congenital anomalies in mid-trimester screening in our low risk population is 3.02 $\%$, which has sensitivity of $87.8 \%$ and specificity of $99.7 \%$. When major anomalies are detected, timely termination of pregnancy have saved the cost and tragedy of losing viable fetus. Longitudinal studies are required to elicit the difference in prevalence between indicated group and low risk population.

\section{REFERENCES}

1. Willocks J, Donald I, Duggan TC, Day N. Foetal cephalometry by ultrasound. J Obstet Gynaecol Br Commonw 1964;71:1120. PMID:14117225 DOI:10.1111/j.1471-0528.1964.tb04236.x [Pubmed]

2. Campbell S, Pearce JM. Ultrasound visualization of congenital malformations. Br Med J 1983;39:322-31.

3. Fetal Imaging. In: Williams Obstetrics. 24th Edition. New York: Mc Graw Hill; 2014.p.194-227. 
4. Saari-Kemppainen A, Karjalainen O, Ylöstalo P, Heinonen OP. Ultrasound screening and perinatal mortality: controlled trial of systematic one-stage screening in pregnancy. The Helsinki Ultrasound Trial. Lancet 1990 Aug;336(8712):387-91. PMID:1974940 DOI:10.1016/0140-6736(90)91941-3 [Pubmed]

5. Eik-Nes SH, Okland O, Aure JC, Ulstein M; Ultrasound screening in pregnancy: a randomized controlled trial. Lancet 1984 Jun.1 (8390):1347. PMID:6145038 DOI:10.1016/s01406736(84)91834-8

6. World Health Organization. Congenital anomalies. Fact sheet No 370. October 2012 http://www.who.int/mediacentre/ factsheets/fs370/en/index.html, accessed $29^{\text {th }}$ April 2015).

7. Termination of Pregnancy for Fetal Abnormality in England, Scotland and Wales. Royal College of Obstetricians and Gynaecologists 2010; p.1-35.

8. Crane JP, LeFevre ML, Winborn RC. et al. A randomized trial of prenatal ultrasonographic screening: impact on detection, management, and outcome of anomalous fetuses. The RADIUS Study Group. Am J Obstet Gynecol 1994 Aug;171(2):392-9. PMID:8059817 DOI:10.1016/s0002-9378(94)70040-0 [Pubmed]

9. Gomez KJ, Copel JA. Ultrasound screening for fetal structural anomalies. Curr Opin Obstet Gynecol 1993 Apr; 5(2):204-10. PMID:8490090 [Pubmed]

10. Marden PM, Smith DW, McDonald MJ. Congenital anomalies in new born infant, including minor variations. J Pediatr 1964;64:357-72.

11. Kaback MM. The utility of prenatal diagnosis. In: Rodeck $\mathrm{CH}$, Nicolaides KH (eds). Prenatal diagnosis. New York: John Wiley; 1984.p.53-64. [Google Scholar]

12. Morrison I. Perinatal mortality: basic considerations. Semin Perinatol 1985 Oct;9(4):144-50. PMID: 4059932 [Indexed for MEDLINE].

13. Ewigman BG, Crane JP, Frigoletto FD, Le Fevre ML, Bain RP, McNellis D. Effect of prenatal ultrasound screening on perinatal outcome. RADIUS Study Group. N EngI J Med 1993;329:821-7.

14. Rosendahl H, Kivenen S. Antenatal detection of congenital malformations by routine ultrasonography. Obstet Gynecol 1989;73:947-51.

15. Levi S, Hyjazi Y, Schaapst JP, Defoort P, Coulon R, Buekens P. Sensitivity and specificity of routine antenatal screening for congenital anomalies by ultrasound: the Belgian multicentric study. Ultrasound Obstet Gynecol 1991;1:102-10.

16. Chitty LS, Hunt GH, Moore J, Lobb MO. Effectiveness of routine ultrasonography in detecting fetal structural abnormalities in a low risk population. BMJ 1991;303:1165-9.

17. Shirley IM, Bottomley F, Robinson VP. Routine radiographer screening for fetal abnormalities by ultrasound in an unselected low risk population. Br J Radiol 1992;65:564-9.

18. Luck CA. Value of routine ultrasound scanning at 19 weeks: a four year study of 8849 deliveries. BMJ 1992;304:1474-8.

19. Anderson N, Boswell O, Duff G. Prenatal sonography for the detection of fetal anomalies: results of a prospective study and comparison with prior series. AJR Am J Roentgenol 1995;165:943-50.

20. Van Dorsten JP, Husley TC, Newman RB, Menard MK. Fetal anomaly detection by second- trimester ultrasonography in a tertiary center. Am J Obstet Gynecol 1998;178:742-9.

21. http://www.worldlifeexpectancy.com/cause-of-death/ congenital-anomalies/by-country/

22. Malla B.K. One year review study of congenital malformation at birth in maternity Hospital (Prasutigriha), Thapathali, Kathamandu. Kath Univ Med J 2007;5(4):557-60.

23. Aryal S. Pattern of congenital anomalies at birth: a hospital based study in Nepal. $14^{\text {th }}$ World Congress in Fetal Medicine.

24. Anatomic survey of the fetus and its relationship to gestational age - what can be seen and cannot be seen. In Padladini D, Volpe P. Ultrasound of Congenital Fetal Anomalies. First edition. Informa UK Ltd; 2007.p.1-10.

25. Weisz B, Pajkrt E, Jauniaux E. Early detection of fetal structural abnormalities. Reprod Biomed Online 2005;10(4):541-553. DOI:10.1016/s1472-6483(10)60832-2

26. Hegge FN, Franklin RW, Watson PT, Calhoun BC: An evaluation of the time of discovery of fetal malformations by an indication based system for ordering obstetric ultrasound. Obstet Gynecol 1989;74:21-4.

27. Magriples U, Copel JA. Accurate detection of anomalies by routine ultrasonography in an indigent clinic population. Am J Obstet Gynecol 1998;179(4):978-81. DOI:10.1016/s00029378(98)70201-7 